\title{
In vitro and in silico Evaluation of Some Natural Molecules as Potent Glutathione Reductase Inhibitors
}

\author{
Tuba Aydın (D) 1,* \\ ${ }^{1}$ Department of Pharmacognosy, Faculty of Pharmacy, Ağrı İbrahim Çeçen University, Agri, Turkey
}

\begin{abstract}
Glutathione reductase inhibitors are very popular antimalarial and anticancer agents. In this study, in vitro inhibition effects of $\beta$-sitosterol, stigmasterol, diosgenin and jervine which containing steroidal structure were determined against glutathione reductase enzyme. $\beta$-sitosterol, diosgenin and jervine were isolated from Veratrum album and stigmasterol was isolated from Artemisia dracunculus L. by chromatographic methods. According to the results obtained, $\mathrm{IC}_{50}$ values of $\beta$-sitosterol, stigmasterol, diosgenin and jervine were found as $1.2580,5.2116,0.1916$ and $0.7701 \mu \mathrm{M}$, respectively. Among test compounds, diosgenin showed the strongest inhibitory effect against glutathione reductase with Swissdock docking figure. In current study first time, $\beta$-sitosterol, stigmasterol, diosgenin and jervine were found to be much more glutathione reductase inhibitors.
\end{abstract}

\section{ARTICLE HISTORY}

Received: October 1, 2019

Revised: November 16, 2019

Accepted: December 15, 2019

\section{KEYWORDS}

Secondary metabolites,

Glutathione reductase,

Inhibition,

Docking

\section{INTRODUCTION}

Glutathione reductase (GR, EC 1.8.1.7), found in most organism is an important homodimeric flavoprotein and an antioxidant enzyme in protection a critical intracellular reducing environment against oxidative stress. It catalyzes the reduced glutathione (GSH) generation from oxidized glutathione using nicotinamide ademine dinucleotide phosphate (NADPH). Oxidized glutathione is generated via the oxidation of GSH by oxidants such as reactive oxygen species (ROS) that occur during oxidative stres. The cell is protected against oxidative stress through discontinuation of oxidants by GSH. GSH prevents the removal of oxygen radicals and lipid intracellular peroxidation. It is a reaction partner for the detoxification of endobiotics and xenobiotics, and is the mode of storage and transport of cysteine. It has important functions in the protection of the cell against oxidative stress, in the maintenance of thiol redox potential in the cell and in the production of deoxyribonucleotides. The lack of GR and GSH leads to oxidative damage in the cell, which can cause many diseases such as malaria and cancer [1-5].

Malaria is an essential worldwide most dangerous disease and seen especially in tropical regions. The most fatal malaria parasite is Plasmodium falciparum. The antimalarial drug developing is very difficult due to this parasite has high mutation rating [6]. Because, when the drugs destroy sensitive parasites, the resistant mutant parasites reproduce and infect other host.

CONTACT: Tuba AYDIN $₫$ taydin@agri.edu.tr Đ Department of Pharmacognosy, Faculty of Pharmacy, Ağrı İbrahim Çeçen University, Agri, Turkey 
It has been reported in the literature, $P$. falciparum developed resistance to chlorokine, which is commonly used as an antimalarial drug [7]. Antimalarial drugs target GR enzyme inhibition and host cells in the malaria parasites. GSH plays a fundamental role in antioxidant defense in both malaria parasite and host cells [6].

The steroidal compounds $\beta$-sitosterol (1), stigmasterol (2), diosgenin (3) and jervine (4) are important bioactive natural products that are quite common in plants and animals (Figure 1) $[8,9]$. Jervine is the major active steroidal alkaloid compound found in Veratum species belonging to the Liliaceae family. It was reported that jervine is a teratogenic ingredient responsible from the malformation in birth after Veratrum species were consumed by pregnant animals [10]. It has been determined to inhibit the hedgehog signaling pathway, which is directly associated with cancer cell proliferation [11]. $\beta$-sitosterol, a steroid found in almost all plant species, has been reported to display a wide variety of biological activities, such as estrogenic, immunomodulatory, anti-arthritic, antioxidant, and anti-ulcer [9, 12-14].

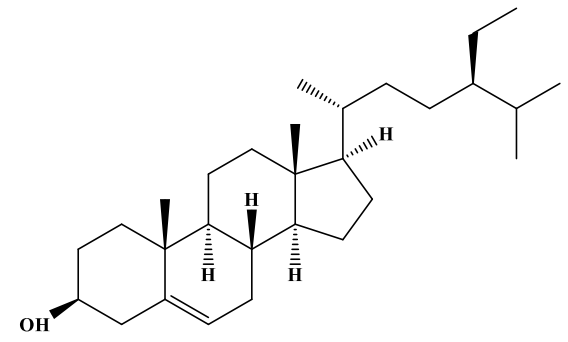

1

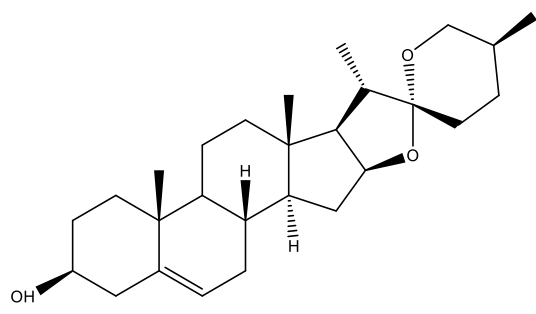

3

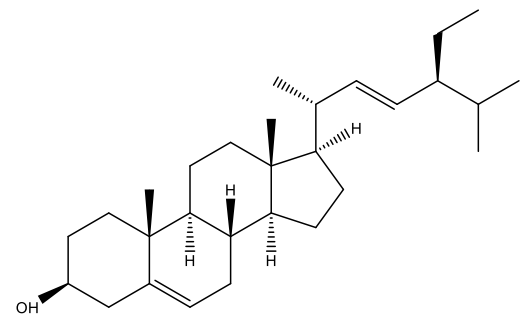

2

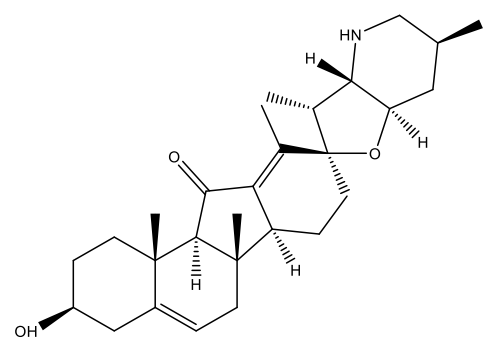

4

Figure 1. The chemical structures of test compounds 1-4. $\beta$-sitosterol (1); stigmasterol (2); diosgenin (3); jervine (4).

Diosgenin, which is used as a starting material for the synthesis of hormones cortisone and progesterone, is a very important natural steroidal sapogenin using in synthesize of new synthetic drugs. It has proapoptotic and anticancer properties [15]. In the previous study by our team, the stigmasterol was isolated from tarragon (Artemisia dracunculus L.) [16]. Stigmasterol is a common plant steroid and has anti-inflammatory and anti-angiogenic activities [17].

In this study, we have tried to find out that $\beta$-sitosterol, stigmasterol, diosgenin and jervine can enter the enzyme active site more easily compared to bulky molecules such as NADPH and GSH, which are the substrates of GR. Thus, it was considered to evaluate these substances as GR inhibitors and to obtain important pharmacological data. Compounds 1-4 are important steroidal bioactive natural compounds, and no studies have been conducted related to the inhibitory effect of these metabolites on GR enzyme. In study first time, the inhibitory effects of $\beta$-sitosterol, stigmasterol, diosgenin and jervine were investigated on the GR enzyme. 


\section{MATERIAL and METHODS}

\subsection{Plant Materials and Chemicals}

As in our previous study, $\beta$-sitosterol, diosgenin and jervine compounds were isolated from rhizomes of Veratrum album and stigmasterol was isolated from Artemisia dracunculus L. $[9,16]$. GR enzyme was purchased from Sigma-Aldrich. All other chemicals used in the study were purchased commercially from Tekkim and Sigma-Aldrich.

\subsection{Extraction and Isolation}

$\beta$-sitosterol, diosgenin and jervine compounds were purified from the acetone extract of Veratrum album according to the procedure in our 2014 study [9]. The stigmasterol was purified from the dichloromethane extract of Artemisia dracunculus L. according to the procedure in our previous study [16]. The spectroscopic findings of the compounds were showed as in the our previous study $[9,16]$.

\subsection{Inhibition of GR}

GR enzyme activity was measured by Beutler's method [18]. An enzyme unit was defined as $1 \mu \mathrm{M}$ NADPH oxidation per minute under test conditions $\left(25^{\circ} \mathrm{C}, \mathrm{pH}: 8.0\right)$. Using a spectrophotometer, a time of 3 minutes was determined at $340 \mathrm{~nm}$ absorbance. Different inhibitor concentrations were used and compounds were tested in triplicate at same process. Control cuvette activity was accapted as $100 \%$ in the absence of inhibitor. An Activity $\%-[$ Inhibitor] graph was drawn for each inhibitor [19,20].

\subsection{In silico Docking Studies}

In silico docking studies were performed in order to investigate the interactions between structure containing molecules and amino acid residues within the GR active site. In silico docking figures were taken from Swissdock.

\section{RESULTS and DISCUSSION}

GR is a primary enzyme which maintains the reduced state of cell. Therefore lack of GR is be directly associated with various disease related to oxidative damage [21]. In this study, we report in vitro inhibitory effects of the steroidal natural compounds $\beta$-sitosterol, stigmasterol, diosgenin and jervine on GR enzyme. These compounds were found to be highly potent inhibitors of GR enzyme at micromolar level as shown in the Table 1 . The $\mathrm{IC}_{50}(\mu \mathrm{M})$ values of the compounds was determined as 1.2580, 5.2116, 0.1916, 0.7701 for $\beta$-sitosterol, stigmasterol, diosgenin and jervine respectively. The $\mathrm{IC}_{50}$ value of the $N, N$-bis(2-chloroethyl)- $N$-nitro used as reference substance was obtained from the literature as $647 \mu \mathrm{M}$ [22].

Table 1. $\mathrm{IC}_{50}$ values, FullFitness and Estimated $\Delta \mathrm{G}$ scores of test compounds on GR enzyme.

\begin{tabular}{lccc}
\hline Inhibitor & $\mathrm{IC}_{50}, \mu \mathrm{M}$ & FullFitness, kcal/mol & $\begin{array}{c}\text { Estimated } \Delta \mathrm{G}, \\
\mathrm{kcal} / \mathrm{mol}\end{array}$ \\
\hline$\beta$-sitosterol & 1.2580 & -2327.41 & -7.30 \\
Stigmasterol & 5.2116 & -2334.39 & -6.76 \\
Diosgenin & 0.1916 & -2347.70 & -8.24 \\
Jervine & 0.7701 & -2347.71 & -7.75 \\
$N, N$-Bis(2-chloroethyl)- $N$-nitrosourea & 647 & - & - \\
\hline
\end{tabular}

As we were unable for the moment to crystallize a GR in complex with one of the natural steroidal structure containing molecules, we performed in silico docking studies in order to investigate the interactions between natural steroidal structure containing molecules and amino acid residues within the GR active site. To this end, fully flexible docking methodology for 
both receptor residues (1GRA pdb file was used for the target structure) and docked ligands was used by FullFitness and Estimated $\Delta \mathrm{G}$ which was implemented with the Swissdock. $\beta$ sitosterol, stigmasterol, diosgenin and jervine were docked at the binding site of the target (hGR). FullFitness and Estimated $\Delta \mathrm{G}$ scores of docked inhibitors at hGR targets and corresponding binding interactions were shown in Table 1. Also diosgenin docking figure of GR enzyme was shown in Figure 2.

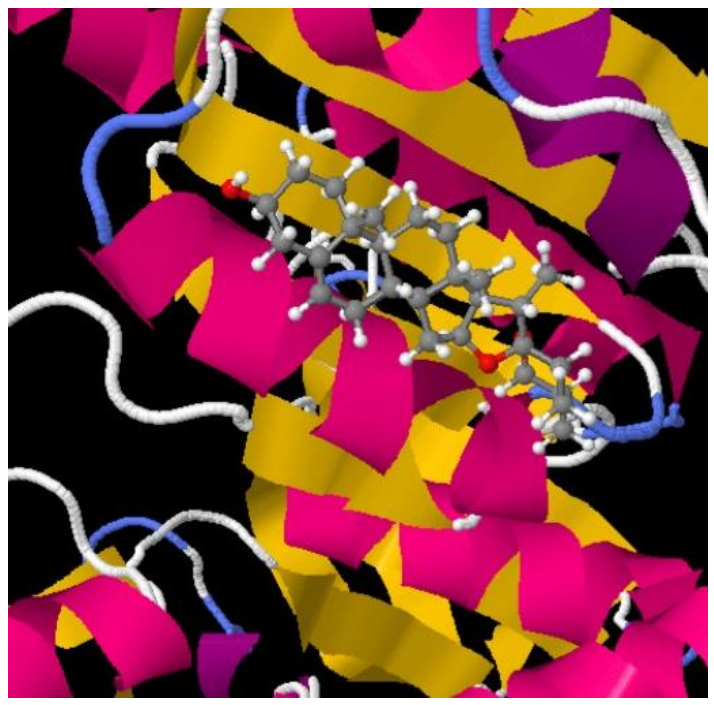

Figure 2. GR enzyme with diosgenin docking figure.

Among the test compounds, the diosgenin showed the strongest effect and stigmasterol showed the weakest effect. When we compare these results with the docking results, docking supports the results that diosgenin is the most potent GR inhibitor. Besides, it appears that the diosgenin is a stronger GR inhibitor than the reference compound $N, N$-bis(2-chloroethyl)- $N$ nitrosourea.

In literature, $\mathrm{IC}_{50}$ values of 1,4-naphthoquinone, 4-nitrobenzothiadiazole and methylene blue which are inhibitors of $P$. falciparum GR, have been reported as $2.71,8.38$ and $19.23 \mu \mathrm{M}$ respectively. These inhibitors were greatly reduced GSH formation [4]. In a study of some $\mathrm{N}$ methyl pyrrole derivatives, 0.104 to $4.942 \mu \mathrm{M}$ results were obtained for GR enzyme [23]. Similar results were obtained in other studies on GR enzyme of natural substances such as thiamine, tyrosine, dopamine, lysine and glutamic acid $[24,25]$. These values are similar to our results.

In terms of structure and activation relationship, steroidal molecules with little electron density have shown better GR inhibitor effect. The only difference in the chemical structure of 1 and 2 compounds is the double bond in the stigmasterol. According to results, $\beta$-sitosterol with $\mathrm{IC}_{50}$ value $1.2580 \mu \mathrm{M}$ is a more potent GR inhibitor than stigmasterol. This result can be interpreted as stigmasterol has higher $\mathrm{IC}_{50}$ value because its double bonds is surrounded by hydrophobic amino acids. GR has a better inhibitory effect on structures with less electron density. Jervine has more electronegative atoms. Therefore, it has less interaction with the active site of GR enzyme. In the current study, $\mathrm{IC}_{50}$ results support this.

The results of our study showed that diosgenin was a very potent GR inhibitor with an $\mathrm{IC}_{50}$ value, $0.1916 \mu \mathrm{M}$ (3376 times more effective than the reference molecule). So we may suggest to diosgenin as potent GR inhibitor. Diosgenin is a raw material in the drug industrial that using in the synthesis of steroidal agents such as progesterone, testosterone, norethisterone and glucocorticoids. It has cardioprotective, anticancer, antiaging and contraceptive properties and high economic value. Progesterone which produced by many pharmaceutical companies is synthesized from diosgenin [26]. 


\section{CONCLUSION}

In the current study, it has been presented $\beta$-sitosterol, stigmasterol, diosgenin and jervine as novel GR inhibitors that have $\mathrm{IC}_{50}$ values at micromolar level. The most widely used anticancer drug $N, N$-bis(2-chloroethyl)- $N$-nitrosourea in the literature has an $647 \mu \mathrm{M} \mathrm{IC}_{50}$ value against the GR enzyme. However, this drug which is used as a GR inhibitor, leads to toxicity and inhibition of DNA synthesis [22]. We report natural steroidal compounds as novel natural GR inhibitors. The $\mathrm{IC}_{50}$ values of the substances used in the study were found to be significantly lower than the positive control so these compounds were evaluated as strong inhibitors. Strong inhibitors may exhibit inhibitory effects at low concentrations, therefore it is thought that their side effects will be less. In this study, the natural steroidal molecules were exhibited much potent inhibitory activities against GR with $\mathrm{IC}_{50}$ values ranging between 0.1916 and 5.2116 $\mu \mathrm{M}$. Inhibition of GR leads to death of malaria parasite and cancer cell due to an abnormal increase in ROS levels. Therefore strong GR inhibitors are very important for antimalarial and anticancer drug research and development.

\section{Acknowledgements}

This work study was presented as a summary in the $9^{\text {th }}$ Annual European Pharma Congress, Madrid, 2017. The author gratefully thanks to Swissdock for data. The author faithfully thanks to Dr. Ahmet Cakir for supportings in the structure characterization and Dr. Murat Senturk for supportings in the enzyme inhibition researchs.

\section{Orcid}

Tuba AYDIN (iD) https://orcid.org/0000-0002-7653-6480

\section{REFERENCES}

[1]. Shahi, Y. Samadi, F.M., Mukherjee, S. (2019). The influence of Tumor Necrosis Factoralpha gene polymorphism on oxidative stress in patients with oral precancerous lesions and oral cancer. Gene Rep, 17, 1-8. doi: doi.org/10.1016/j.genrep.2019.100525

[2]. Tsai, Y.C., Hong, C.Y., Liu, L.F., Kao C.H. (2005). Expression of ascorbate peroxidase and glutathione reductase in roots of rice seedlings in response to $\mathrm{NaCl}$ and $\mathrm{H}_{2} \mathrm{O}_{2}$. J Plant Physiol, 162, 291-299. doi: 10.1016/j.jplph.2004.06.004

[3]. Meister A. Anderson M.E. (1983). Glutathione, Annu Rev Biochem., 52, 711-760. doi: 10.1146/annurev.bi.52.070183.003431

[4]. Schirmer, R.H., Muller, J.G., Krauthsiegel, R.L., (1995). Disulfide-reductase inhibitors as chemotherapeutic - agents - the design of drugs for trypanosomiasis and malaria. Angew Chem Int Edit., 34, 141-154. doi: doi.org/10.1002/anie.199501411

[5]. Bohme, C.C., Arscott, L.D., Becker, K., Schirmer, R.H. (2000). Jr. Williams, C.H. Kinetic characterization of glutathione reductase from the malarial parasite Plasmodium falciparum. Comparison with the human enzyme. J Biol Chem., 275, 37317-37323. doi: 10.1074/jbc.M007695200

[6]. Burkard, L., Scheuermann, A., Simithy, J., Calderon, A.I. (2016). Development of a functional assay to detect inhibitors of Plasmodium falciparum glutathione reductase utilizing liquid chromatography-mass spectrometry. Biomed Chromatogr., 30, 543-547. doi: doi.org/10.1002/bmc.3580

[7]. Talisuna, A.O., Okello, P.E., Erhart, A., Coosemans, M., D'Alessandro, U. (2007). Intensity of malaria transmission and the spread of Plasmodium falciparum-resistant malaria: A review of epidemiologic field evidence. Am J Trop Med Hyg., 77, 170-180. WOS:00025 2212600027

[8]. Hainley, C.A., Filer, C.N. (2017). Selective D ring side chain tritiation of steroidal natural products. J Radioanal Nucl Ch., 313, 467-472. doi:10.1007/s10967-017-5322-y 
[9]. Aydin, T., Cakir, A., Kazaz, C., Bayrak, N., Bayir, Y., Taskesenligil, Y. (2014). Insecticidal metabolites from the rhizomes of Veratrum album against adults of Colorado Potato Beetle. Leptinotarsa decemlineata, Chem Biodivers., 11, 1192-1204. doi:doi.org/10.1002/cbdv.201300407

[10]. Lee, S.T., Panter, K.E., Gaffield, W., Stegelmeier, B.L. (2003). Development of an enzyme-linked immunosorbent assay for the Veratrum plant teratogens: Cyclopamine and jervine. J Agr Food Chem., 51, 582-586. doi: doi.org/10.1021/jf020961s

[11]. Khanfar, M.A., El Sayed, K.A. (2013). The Veratrum alkaloids jervine, veratramine, and their analogues as prostate cancer migration and proliferation inhibitors: biological evaluation and pharmacophore modeling. Med Chem Res, 22, 4775-4786. doi: 10.1007/s00044-013-0495-6

[12]. Yamamoto M. Masui T. Sugiyama K. Yokota M. Nakagomi K. Nakazawa H. (1991). Antiinflammatory active constituents of Aloe arborescens Miller. Agr Biol Chem Tokyo, 55, 1627-1629. doi.org/10.1271/bbb1961.55.1627

[13]. Bouic, P.J.D., Etsebeth, S., Liebenberg, R.W., Albrecht, C.F., Pegel, K., VanJaarsveld, P.P. (1996). Beta-sitosterol and beta-sitosterol glucoside stimulate human peripheral blood lymphocyte proliferation: Implications for their use as an immunomodulatory vitamin combination. Int J Immunopharmaco., 18, 693-700. doi: doi.org/10.1016/S01920561(97)85551-8

[14]. Ju, Y.H., Clausen, L.M., Allred, K.F., Almada, A.L., Helferich, W.G. (2004). betaSitosterol, beta-sitosterol glucoside, and a mixture of beta-sitosterol and beta-sitosterol glucoside modulate the growth of estrogen-responsive breast cancer cells in vitro and in ovariectomized athymic mice. J Nutr., 134, 1145-1151. doi: doi.org/10.1093/jn/134.5.11 45

[15]. Sethi, G., Shanmugam, M.K., Warrier, S., Merarchi, M., Arfuso, F., Kumar, A.P., Bishayee, A. (2018). Pro-apoptotic and anti-cancer properties of diosgenin: A comprehensive and critical review. Nutrients, 10, 645. doi.org/10.3390/nu10050645

[16]. Aydin, T., Yurtvermez, B., Senturk, M., Kazaz C., Cakir, A. (2019). Inhibitory effects of metabolites isolated from Artemisia dracunculus L. against the human carbonic anhydrase I (hCA I) and II (hCA II). Rec. Nat. Prod., 13, 216-225. doi: doi.org/10.25135/rnp.102.1 8.07.329

[17]. Kangsamaksin, T., Chaithongyot, S., Wootthichairangsan, C., Hanchaina, R., Tangshewinsirikul, C., Svasti, J. (2017). Lupeol and stigmasterol suppress tumor angiogenesis and inhibit cholangiocarcinoma growth in mice via downregulation of tumor necrosis factor-alpha. PLoS One. 12, e0189628. doi: doi.org/10.1371/journal.pone.0189 628

[18]. Beutler, E. (1984). Red cell metabolism. A manual of biochemical methods. Grune and Stratton Inc, Orlando. ISBN: 08089167269780808916727

[19]. Balaydin, H.T., Ozil, M., Senturk, M. (2018). Synthesis and glutathione reductase inhibitory properties of 5-methyl-2,4-dihydro-3H-1,2,4-triazol-3-one's aryl Schiff base derivatives. Arch Pharm., 351, 1-8. doi: doi.org/10.1002/ardp.201800086.

[20]. Coban, T.A., Senturk, M., Ciftci, M., Kufrevioglu, O. I. (2007). Effects of some metal ions on human erythrocyte glutathione reductase: an in vitro study. Protein Peptide Lett., 14, 1027-1030. doi: doi.org/10.2174/092986607782541060

[21]. Ray, A., Chatterjee, S., Mukherjee, S., Bhattacharya, S. (2014). Arsenic trioxide induced indirect and direct inhibition of glutathione reductase leads to apoptosis in rat hepatocytes. Biometals., 27, 483-494. doi: doi 10.1007/s10534-014-9722-y

[22]. Seefeldt, T., Zhao, Y., Chen, W., Raza, A.S., Carlson, L., Herman, J., Stoebner, A., Hanson, S., Foll, R., Guan, X.M. (2009). Characterization of a novel dithiocarbamate 
glutathione reductase inhibitor and its use as a tool to modulate intracellular glutathione. J Biol Chem., 284, 2729-2737. doi: 10.1074/jbc.M802683200

[23]. Kocaoglu, E., Talaz, O., Cavdar, H., Senturk, M., Supuran, C.T., Ekinci, D. (2018). Determination of the inhibitory effects of $\mathrm{N}$-methylpyrrole derivatives on glutathione reductase enzyme. J Enzym Inhib Med Chem., 34, 51-54.

doi.org/10.1080/14756366.2018.1520228.

[24]. Senturk, E., Urçar, H., Senturk, M., Yildirim, S., Gul, M., (2016). Bovine liver tissue on glutathione reductase enzyme determination of effects of thiamine, tyrosine, dopamine and adrenaline. Acta Physiol., 218, 58. WOS:000383578300152

[25]. Cakmak, R., Durdagi, S., Ekinci, D., Senturk, M., Topal, G. (2011). Design, synthesis and biological evaluation of novel nitroaromatic compounds as potent glutathione reductase inhibitors. Bioorg Med Chem Lett., 21, 5398-5402. doi: doi.org/10.1016/j.ejmech.2009.03.006

[26]. Chaudhary, S., Chaudhary, P.S., Chikara, S.K., Sharma, M.C., Iriti, M. (2018). Review on Fenugreek (Trigonella foenum-graecum L.) and its important secondary metabolite diosgenin. Not Bot Horti Agrobo., 46, 22-31. doi: doi.org/10.15835/nbha46110996 